\title{
Response concerning 'Letter to editor' by Ni et al. (2017), Arch Orthop Trauma Surg. DOI 10.1007/s00402-017-2710-2
}

\author{
Kadir Gok $^{1} \cdot$ Sermet Inal $^{2} \cdot$ Arif Gok $^{3} \cdot$ Eyyup Gulbandilar $^{4}$
}

Received: 15 June 2017 / Published online: 29 July 2017

(c) Springer-Verlag GmbH Germany 2017

\section{Dear Editor,}

We carefully read the "Letter to editor" about our article [1] by Ni et al. [2]. We are grateful to the authors for their contribution to different perspectives. They claimed that our work was modeled by Solid-Works software for only triangle configuration of femoral neck fracture. However, we have explained about this situation that "Gok and Inal researched what the best stable fixation practice might be by applying five different screw configuration types on the femoral neck fracture model with finite element analysis (FEA) method." in the last paragraph of introduction section [3]. We think that is been overlooked during the reading of $\mathrm{Ni}$ et al.

Thank you for allowing us to correct this situation.

\section{Compliance with ethical standards}

Conflict of interest The authors declare that they have no competing interests.

\section{References}

1. Gok K, Inal S, Gok A, Gulbandilar E (2017) Comparison of effects of different screw materials in the triangle fixation of femoral neck fractures. J Mater Sci Mater Med 28(5):81

2. Ni J, Wang X, Yuang Y, Liu H, Zhou L (2017) Letter to the editor concerning "Femoral neck fracture osteosynthesis by the biplane double-supported screw fixation method (BDSF) reduces the risk of fixation failure: clinical outcomes in 207 patients' 'by Filipov O, Sommer C et al (2017). Arch Orthop Trauma Surg. doi:10.1007/s00402-017-2710-2

3. Gok K, Inal S (2015) Biomechanical comparison using finite element analysis of different screw configurations in the fixation of femoral neck fractures. Mech Sci. 6(2):173-179. doi:10.5194/ ms-6-173-2015
Kadir Gok

kadir.gok@cbu.edu.tr

1 Department of Mechanical and Manufacturing Engineering, Hasan Ferdi Turgutlu Technology Faculty, Manisa Celal Bayar University, Manisa 45400, Turkey

2 Department of Orthopaedic Surgery, School of Medicine, Dumlupinar University, Campus of Evliya Celebi, Kutahya 43100, Turkey

3 Department of Mechanical Engineering, Technology Faculty, Amasya University, Amasya 05000, Turkey

4 Department of Computer Engineering, Faculty of Engineering and Architecture, Eyyup Gulbandilar, Eskisehir Osmangazi University, Meselik Campus, Eskisehir 26480, Turkey 